\title{
Earth Mat Design for 132/33Kv Substation in Rivers State Using ETAP
}

\author{
C.S. Esobinenwu, B.O.H. Akinwole, C.O. Omeje, \\ Department of Electrical/Electronic Engineering \\ University of Port Harcourt,
}

Port Harcourt, Nigeria.

\begin{abstract}
Earthing is an important aspect of every substation construction. Earth Mat is preferable to large substations because of space saving on the ground level due to substantial reduction of earth pits which leads to ease of coordination. Earth Mat minimizes the danger of high step or touch voltages in critical operating areas or places that are frequently used by people. Thus properly designed earthing system capable of dissipating large currents safely to earth is required, regardless of the fault type. This paper presents the design of earthing systems for the $132 / 33 \mathrm{Kv}$ substation in Rivers state of Nigeria and the review of substation practices with special reference to safety and development criteria for safe design. A real time case study has been considered and the design was done using ETAP (Electrical Transients Analyzer Program). Simulation using ETAP eradicates the error that is inherent in manual operational method that is mostly used in various substations.
\end{abstract}

Keywords: Earth Mat, Step potential, touch potential, Earthing, ground resistance, electrodes, and simulations.

\section{0) Introduction}

The earthing system of an electrical substation comprises all interconnected earthing facilities of a specific area with the earthing grid as its main element. In general, it consists of a mesh of interconnected cylindrical conductors, horizontally buried and supplemented by ground rods vertically thrusted in specific places of the installation site [1].
The accurate design of an earthing system is essential to assure the safety of the persons, to protect the equipment and to avoid interruptions in the power supply. Thus, the apparent electrical resistance of the earthing system must be low enough to guarantee that fault currents dissipate mainly through the earthing electrode into the ground, while the values of electrical potentials between close points on the earth surface that can be connected by a person must be kept under certain maximum safe limits $[1,2]$. The earthing system in a plant / facility is very important for few reasons, all of which are related to either the protection of people and equipment and/or the optimal operation of the electrical system. These include:

- Equipotential bonding of conductive objects (e.g. metallic equipment, buildings, piping etc) to the earthing system that prevents the presence of dangerous voltages between objects (and earth).

- The earthing system provides a low resistance return path for earth faults within the plant, which protects both personnel and equipment

- $\quad$ For earth faults with return paths to offsite generation sources, a low resistance earthing grid relative to remote earth prevents dangerous ground potential rises (touch and step potentials)

- The earthing system provides a low resistance path (relative to remote earth) for voltage transients such as lightning and surges / over voltages 
- $\quad$ Equipotential bonding helps prevent electrostatic build up and discharge, which can cause sparks with enough energy to ignite flammable atmospheres

- The earthing system provides a reference potential for electronic circuits and helps reduce electrical noise for electronic, instrumentation and communication systems

This calculation is based primarily on the guidelines provided by IEEE Std 80 (2000), "Guide for safety in AC substation earthing". Lightning protection is excluded from the scope of this calculation (refer to the specific lightning protection calculation for more details).

The earthing calculation aids in the proper design of the earthing system. Using the results of this calculation, one can:

- Determine the minimum size of the earthing conductors required for the main earth grid

- Ensure that the earthing design is appropriate to prevent dangerous step and touch potentials (if this is necessary)

This calculation should be performed when the earthing system is being designed. It could also be done after the preliminary design has been completed to confirm that the earthing system is adequate, or highlight the need for improvement / redesign. Ideally, soil resistivity test results got from the site will be available for use in touch and step potential calculations (if necessary).

The sizing of earthing conductors should always be performed, but touch and step potential calculations (per IEEE Std 80 for earth faults with a return path through remote earth) are not always necessary.

For example, when all electricity is generated on-site and the HV/MV/LV earthing systems are interconnected, then there is no need to do a touch and step potential calculation. In such a case, all earth faults would return to the source via the earthing system (notwithstanding some small leakage through earth).
However, where there are decoupled networks (e.g. long transmission lines to remote areas of the plant), then touch and step potential calculations should be performed for the remote area only.

In [3] it was stated that a good earthing system has a low resistance to remote earth to minimize the ground potential rise (GPR).

In order for an earthing design to be safe, it needs to provide a way to carry the electric currents into the ground under both normal and faulted conditions. Also, it must provide assurance that a person in the vicinity would not be endangered. Because there is no simple relation between the resistance of the earthing system and the maximum shock current a person can experience, a complete analysis must be done to consider many different aspects such as the location of the ground electrodes, soil characteristics. According to [4] it was assumed that any earthing object can be safely touched, but that is not always the case. A low substation ground resistance doesn't guarantee safety. There are no simple relation between the ground system resistance and the maximum shock current that a person might be exposed to. In [5] different formulae to calculate the earth resistance of several configurations of rods; a short horizontal wire, a buried horizontal plate, a horizontal strip and a ring of wire were proposed.

Recently studies of the horizontal earth electrode using the transmission line model were carried out. Their results showed that the voltage drop along the horizontal electrode was significant due to inductance, but only a certain length, the "effective length", contributed to current dissipation. The effective length was shown to increase with increasing soil resistivity [6].

In [7], an analytical model of a horizontal earth electrode based on an equivalent transmission line was used and it was demonstrated that no significant benefit could be achieved by extending the electrode length beyond the effective length. 
A definition of the effective length as the length at which the voltage reaches $3 \%$ of its value at the current injection point was also proposed in [8]. An analytical expression was proposed to calculate the effective length of a horizontal earth electrode based on a formula from earlier work presented in [9].

\section{0) Conventional Earthing \& Earth Mat Design}

\section{A. Conventional Earthing}

The conventional system of Earthing calls for digging of a large pit into which a GI pipe or a copper plate is positioned amidst layers of charcoal and salt. It is cumbersome to install only one or two pits in a day. Types of conventional Earthing are shown below:
a. Pipe Earthing
b. GI Pipe Earthing
c. Cast Iron Plate Earthing
d. Copper Plate Earthing

The conventional system of GI pipe Earthing or copper plate Earthing requires maintenance and pouring of water at regular interval.

\section{B. Earth Mat design}

Substation earth system will have a combination of buried horizontal conductors in rows and columns and vertical electrodes. A sold metallic plate or a system of closely spaced bare conductors that are connected to and often placed in shallow depths above a ground grid or elsewhere at the earth's surface, in order to obtain an extra protective measure minimizing the danger of the exposure to high step or touch voltages in a critical operating area or places that are frequently used by people. Grounded metal gratings placed on or above the soil surface, or wire mesh placed directly under the surface material, are common form of a ground mat.
3.0 ) Recommendations for Resistance Values from Different Standards:

A. NEC.

The National Electric Code (NEC), Section 250-84, requires that a single electrode consisting of rod, pipe or plate that does not have a resistance to ground of 25 ohms or less shall be augmented by one additional electrode of the type listed in section 250-81 or 250-83. Multiple electrodes should always be installed so that they are more than six feet $(1.8 \mathrm{~m})$ apart. Spacing greater than six feet will increase the rod efficiency. Proper spacing of the electrodes will ensure that the maximum amount of fault current can be safely discharged into the earth.

\section{B. CPWD (CENTRAL PUBLIC WORKS}

\section{DEPARTMENT)}

The earth resistance at each electrode shall be measured. No earth electrode shall have a greater ohmic resistance than $5 \mathrm{ohms}$ as measured by an approved earth testing apparatus. In rocky soil the resistance may be up to $8 \mathrm{ohms}$

Where the above stated earth resistance is not achieved, necessary improvement shall be made by additional provisions, such as additional electrodes, different type of electrode or artificial chemical treatment of soil etc., as may be directed by the Engineer-in-charge

C. IS 3043

The choice of using a common earth or separate earths for the system of different voltages at a transforming point effect:

The probability of breakdown occurring in a transformer between the higher and lower voltage sides due to lighting or other surges and

The safety of consumers or their property supplied by any low voltage system distributed from the station against arises of potential of the earthed neutral by a high voltage system earth fault at the Station. The former risk is reduced by use of a common earth system and the latter danger only arises if the resistance of the earth electrode system 
is not sufficiently low to limit the rise of earth potential to a safe value. There is advantage in using a common earth where the earth electrode resistance, Including the parallel resistance of any bonded metalwork, etc, to earth is $1 \mathrm{ohm}$ or less as is usual at power stations large outdoor substations or substations supplying a network of cables whose sheaths have a low impedance to earth.

\section{0) Calculation Methodology}

This calculation is based on IEEE Std 80 (2000), "Guide for safety in AC substation earthing". There are two main parts to this calculation:

- $\quad$ Earthing grid conductor sizing

- Touch and step potential calculations

IEEE Std 80 is quite descriptive, detailed and easy to follow, so only an overview will be presented here and IEEE Std 80 is consulted for further details

\section{A. Prerequisites.}

The following information is required / desirable before starting the calculation:

- A layout of the site

- Maximum earth fault current into the earthing grid

- Maximum fault clearing time

- Ambient (or soil) temperature at the site

- Soil resistivity measurements at the site (for touch and step only)

- Resistivity of any surface layers intended to be laid (for touch and step only)

\section{B. Earthing Grid Conductor Sizing}

Determining the minimum size of the earthing grid conductors is necessary to ensure that the earthing grid will be able to withstand the maximum earth fault current. Like a normal power cable under fault, the earthing grid conductors experience an adiabatic short circuit temperature rise. However unlike a fault on a normal cable, where the limiting temperature is that which would cause permanent damage to the cable's insulation, the temperature limit for earthing grid conductors is the melting point of the conductor. The minimum conductor size capable of withstanding adiabatic temperature rise associated with earth fault is given by re-arranging IEEE Std 80 Equation 37 represented by (1)

$$
\mathrm{A}=\sqrt{\mathrm{i}^{2} \mathrm{t}\left(\frac{\frac{\alpha_{\mathrm{T}} \rho_{\mathrm{T}} \times 10^{4}}{\mathrm{TCAP}}}{\ln \left[1+\left(\frac{\mathrm{T}_{\mathrm{m}}-\mathrm{T}_{\mathrm{a}}}{\mathrm{K}_{0}+\mathrm{T}_{\mathrm{a}}}\right)\right]}\right)}
$$

Where $A$ is the minimum cross-sectional area of the earthing grid conductor $\left(\mathrm{mm}^{2}\right)$

$\mathbf{i}^{2} \mathbf{t}$ is the energy of the maximum earth fault $\left(\mathrm{A}^{2} \mathrm{~s}\right)$

$\mathbf{T}_{\mathbf{m}}$ is the maximum allowable (fusing) temperature $\left({ }^{\circ} \mathrm{C}\right)$

$\mathbf{T}_{\mathbf{a}}$ is the ambient temperature $\left({ }^{\circ} \mathrm{C}\right)$

$\boldsymbol{\alpha}_{\mathrm{T}}$ is the thermal coefficient of resistivity $\left({ }^{\circ} \mathrm{C}^{-1}\right)$

$\boldsymbol{\rho}_{\mathrm{T}}$ is the resistivity of the earthing conductor $(\mu \Omega . \mathrm{cm})$

$\mathbf{K}_{\mathbf{0}}$ is a constant denoted by $\left(\frac{1}{\boldsymbol{\alpha}_{\mathrm{T}}}-20^{\circ} \mathrm{C}\right)$

TCAP is the thermal capacity of the conductor per unit volume $\left(\mathrm{Jcm}^{-3 o} \mathrm{C}^{-1}\right)$

The material constants $T_{m}, \alpha_{r}, \rho_{r}$ and TCAP for common conductor materials can be found in IEEE Std 80 Table 1. For example. commercial harddrawn copper has material constants:

- $\mathrm{T}_{\mathrm{m}}=1084^{\circ} \mathrm{C}$

- $\alpha_{\mathrm{r}}=0.00381^{\circ} \mathrm{C}^{-1}$

- $\rho_{\mathrm{r}}=1.78 \mu \Omega . \mathrm{cm}$

- $\quad$ TCAP $=3.42 \mathrm{Jcm}^{-3 o} \mathrm{C}^{-1}$.

As described in IEEE Std 80 Section 11.3.1.1, there are alternative methods to formulate this equation, all of which can also be derived from first principles. There are also additional factors that should be considered (e.g. taking into account future growth in 
fault levels), as discussed in IEEE Std 80 Section 11.3.3.

\section{5) Touch and Step Potential Calculations.}

When electricity is generated remotely and there are no return paths for earth faults other than the earth itself, then there is a risk that earth faults can cause dangerous voltage gradients in the earth around the site of the fault (called ground potential rises). This means that someone standing near the fault can receive a dangerous electrical shock due to:

- Touch voltages - there is a dangerous potential difference between the earth and a metallic object that a person is touching

- Step voltages - there is a dangerous voltage gradient between the feet of a person standing on earth

The earthing grid can be used to dissipate fault currents to remote earth and reduce the voltage gradients in the earth. The touch and step potential calculations are performed in order to assess whether the earthing grid can dissipate the fault currents so that dangerous touch and step voltages cannot exist.

\section{Step 1: Soil Resistivity}

The resistivity properties of the soil where the earthing grid will be laid is an important factor in determining the earthing grid's resistance with respect to remote earth. Soils with lower resistivity lead to lower overall grid resistances and potentially smaller earthing grid configurations can be designed (i.e. that comply with safe step and touch potentials). It is good practice to perform soil resistivity tests on the site. There are a few standard methods for measuring soil resistivity (e.g. Wenner four-pin method). A good discussion on the interpretation of soil resistivity test measurements is found in IEEE Std 80 Section 13.4.

Sometimes it isn't possible to conduct soil resistivity tests and an estimate must suffice. When estimating soil resistivity, it goes without saying that one should err on the side of caution and select a higher resistivity. IEEE Std 80 Table 8 gives some guidance on range of soil resistivities based on the general characteristics of the soil (i.e. wet organic soil $=10$ $\Omega . \mathrm{m}$, moist soil $=100 \Omega . \mathrm{m}$, dry soil $=1,000 \Omega . \mathrm{m}$ and bedrock $=10,000 \Omega . \mathrm{m})$.

\section{Step 2: Surface Layer Materials}

Applying a thin layer $(0.08 \mathrm{~m}-0.15 \mathrm{~m})$ of high resistivity material (such as gravel, blue metal, crushed rock, etc) over the surface of the ground is commonly used to help protect against dangerous touch and step voltages. This is because the surface layer material increases the contact resistance between the soil (i.e. earth) and the feet of a person standing on it, thereby lowering the current flowing through the person in the event of a fault.

IEEE Std 80 Table 7 gives typical values for surface layer material resistivity in dry and wet conditions (e.g. $40 \mathrm{~mm}$ crushed granite $=4,000 \Omega . \mathrm{m}$ (dry) and

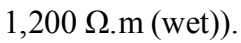

The effective resistance of a person's feet (with respect to earth) when standing on a surface layer is not the same as the surface layer resistance because the layer is not thick enough to have uniform resistivity in all directions. A surface layer derating factor needs to be applied in order to compute the effective foot resistance (with respect to earth) in the presence of a finite thickness of surface layer material. This derating factor can be approximated by an empirical formula as per IEEE Std 80 Equation 27 represented in (2):

$\mathrm{C}_{\mathrm{s}}=1-\frac{0.09\left(1-\frac{\rho}{\rho_{\mathrm{s}}}\right)}{2 \mathrm{~h}_{\mathrm{s}}+0.09}$

Where $C_{s}$ is the surface layer derating factor $\rho$ is the soil resistivity $(\Omega . \mathrm{m})$

$\rho_{\mathrm{s}}$ is the resistivity of the surface layer material $(\Omega . \mathrm{m})$

$h_{s}$ is the thickness of the surface layer (m)

This derating factor will be used later in Step 5 when calculating the maximum allowable touch and step voltages. 


\section{Step 3: Earthing Grid Resistance}

A good earthing grid has low resistance (with respect to remote earth) to minimise ground potential rise (GPR) and consequently avoid dangerous touch and step voltages. Calculating the earthing grid resistance usually goes hand in hand with earthing grid design - that is, you design the earthing grid to minimise grid resistance. The earthing grid resistance mainly depends on the area taken up by the earthing grid, the total length of buried earthing conductors and the number of earthing rods / electrodes.

IEEE Std 80 offers two alternative options for calculating the earthing grid resistance (with respect to remote earth) - 1) the simplified method (Section 14.2) and 2) the Schwarz equations (Section 14.3), both of which are outlined briefly below. IEEE Std 80 also includes methods for reducing soil resistivity (in Section 14.5) and a treatment for concreteencased earthing electrodes (in Section 14.6).

\section{A. Simplified Method.}

IEEE Std 80 Equation 52 gives the simplified method as modified by Sverak to include the effect of earthing grid depth as presented in (3):

$$
\begin{aligned}
R_{g}=\rho\left[\frac{1}{L_{T}}+\frac{1}{\sqrt{20 \mathrm{~A}}}\right. & (1 \\
& \left.\left.+\frac{1}{1+\mathrm{h} \sqrt{\frac{20}{\mathrm{~A}}}}\right)\right](3)
\end{aligned}
$$

Where $R_{g}$ is the earthing grid resistance with respect to remote earth $(\Omega)$

$\rho$ is the soil resistivity $(\Omega . \mathrm{m})$

$\mathrm{L}_{\mathrm{T}}$ is the total length of buried conductors

(m)

A is the total area occupied by the earthing grid $\left(\mathrm{m}^{2}\right)$

$\mathrm{h}$ is the depth of the earthing grid (m)

\section{B. Schwarz Equations.}

The Schwarz equations are a series of equations that are more accurate in modelling the effect of earthing rods / electrodes. The equations are found in IEEE Std 80 Equations 53, 54, 55 and 56, as presented in (4):

$R_{g}=\frac{R_{1} R_{2}-R_{m}^{2}}{R_{1}+R_{2}-2 R_{m}}$

Where $R_{g}$ is the earthing grid resistance with respect to remote earth $(\Omega)$

$\mathrm{R}_{1}$ is the earth resistance of the grid conductors $(\Omega)$

$R_{2}$ is the earth resistance of the earthing electrodes $(\Omega)$

$R_{m}$ is the mutual earth resistance between the grid conductors and earthing electrodes

The values for the grid, earthing electrode and mutual earth resistances are got from (5)-(7):

$$
\begin{gathered}
\mathrm{R}_{1}=\frac{\rho}{\pi \mathrm{L}_{\mathrm{c}}}\left[\ln \left(\frac{2 \mathrm{~L}_{\mathrm{c}}}{\mathrm{a}^{\prime}}\right)+\frac{\mathrm{K}_{1} \mathrm{~L}_{\mathrm{c}}}{\sqrt{\mathrm{A}}}-\mathrm{K}_{2}\right] \\
\mathrm{R}_{2}=\frac{\rho}{2 \pi \mathrm{n}_{\mathrm{r}} \mathrm{L}_{\mathrm{r}}}\left[\ln \left(\frac{4 \mathrm{~L}_{\mathrm{r}}}{\mathrm{b}}\right)-1\right. \\
\left.+\frac{2 \mathrm{~K}_{1} \mathrm{~L}_{\mathrm{r}}}{\sqrt{\mathrm{A}}}\left(\sqrt{\mathrm{n}_{\mathrm{r}}-1}\right)^{2}\right] \\
\mathrm{R}_{\mathrm{m}} \frac{\rho}{\pi \mathrm{L}_{\mathrm{c}}}\left[\ln \left(\frac{2 \mathrm{~L}_{\mathrm{c}}}{\mathrm{L}_{\mathrm{r}}}\right)+\frac{\mathrm{K}_{1} \mathrm{~L}_{\mathrm{c}}}{\sqrt{\mathrm{A}}}-\mathrm{K}_{2}+1\right]
\end{gathered}
$$

Where $\rho$ is the soil resistivity $(\Omega . m)$

$\mathrm{L}_{\mathrm{c}}$ is the total length of buried grid conductors (m) $\mathrm{a}^{\prime}$ is given by $\sqrt{\mathrm{r} .2 \mathrm{~h}}$ for conductors buried at depth $h$ metres and with cross-sectional radius $\mathrm{r}$ metres, or simply $r$ for grid conductors on the surface

A is the total area covered by the grid conductors $\left(\mathrm{m}^{2}\right)$

$\mathrm{L}_{\mathrm{r}}$ is the length of each earthing electrode (m)

$\mathrm{n}_{\mathrm{r}}$ is number of earthing electrodes in area $A$ 
$\mathrm{b}$ is the cross-sectional radius of an earthing electrode (m)

$\mathrm{K}_{1}$ and $\mathrm{K}_{2}$ are constant coefficients depending on the geometry of the grid

The coefficient $\mathrm{K}_{1}$ can be approximated by the following relations given by (8)-(10):

For depth $\mathrm{h}=0, \mathrm{~K}_{1}=-\frac{0.04 \mathrm{~L}}{\mathrm{R}}+1.41(8)$

For depth $h=\frac{1}{10} \sqrt{\mathrm{A}}, \mathrm{K}_{1}=-\frac{0.05 \mathrm{~L}}{\mathrm{R}}+$

For depth $h=\frac{1}{6} \sqrt{A}, K_{1}=-\frac{0.05 \mathrm{~L}}{R}+$

Similarly,

The coefficient $\mathrm{K}_{2}$ can be approximated by the following relations given by (11)-(13):

For depth $\mathrm{h}=0, \quad \mathrm{~K}_{2}=-\frac{0.15 \mathrm{~L}}{\mathrm{R}}+5.50$

For depth

$\mathrm{h}=\frac{1}{10} \sqrt{\mathrm{A}}, \quad \mathrm{K}_{2}=\frac{0.10 \mathrm{~L}}{\mathrm{R}}+4.68$

For depth

$\mathrm{h}=\frac{1}{6} \sqrt{\mathrm{A}}, \quad \mathrm{K}_{2}=\frac{0.05 \mathrm{~L}}{\mathrm{R}}+4.40$

Where in both cases, $\frac{L}{R}$ is the length-to-width ratio of the earthing grid.

\section{Step 4: Maximum Grid Current}

The maximum grid current is the worst case earth fault current that would flow via the earthing grid back to remote earth. To calculate the maximum grid current, you firstly need to calculate the worst case symmetrical earth fault current at the facility that would have a return path through remote earth (call this $I_{k, e}$ ). This can be found from the power systems studies or from manual calculation. Generally speaking, the highest relevant earth fault level will be on the primary side of the largest distribution transformer (i.e. either the terminals or the delta windings).

C. Current Division Factor .

Not all of the earth fault current will flow back through remote earth. A portion of the earth fault current may have local return paths (e.g. local generation) or there could be alternative return paths other than remote earth (e.g. overhead earth return cables, buried pipes and cables, etc). Therefore a current division factor $S_{\mathrm{f}}$ must be applied to account for the proportion of the fault current flowing back through remote earth.

Computing the current division factor is a task that is specific to each project and the fault location and it may incorporate some subjectivity (i.e. "engineering judgement"). In any case, IEEE Std 80 Section 15.9 has a good discussion on calculating the current division factor. In the most conservative case, a current division factor of $\mathrm{S}_{\mathrm{f}}=1$ can be applied, meaning that $100 \%$ of earth fault current flows back through remote earth [10].

The symmetrical grid currentI $\mathrm{g}_{\mathrm{g}}$ is calculated by (14):

$$
\mathrm{I}_{\mathrm{g}}=\mathrm{I}_{\mathrm{k},} \in \mathrm{S}_{\mathrm{f}}
$$

The symmetrical grid current is not the maximum grid current because of asymmetry in short circuits, namely a dc current offset. This is captured by the decrement factor, which can be calculated from IEEE Std 80 Equation 79 that is presented in (15):

$D_{f}=\sqrt{1+\frac{T_{a}}{t_{f}}\left(1-e^{-\frac{2 t f}{T_{a}}}\right)}$

Where $D_{f}$ is the decrement factor

$t_{f}$ is the duration of the fault (s)

$\mathrm{T}_{\mathrm{a}}$ is the dc time offset constant (see below)

The dc time offset constant is derived from IEEE Std 80 Equation 74 which is also presented in (16):

$\mathrm{T}_{\mathrm{a}}=\frac{\mathrm{X}}{\mathrm{R}} \cdot \frac{1}{2 \pi \mathrm{f}}$

Where $\frac{X}{R}$ is the ratio at the fault location

$\mathrm{f}$ is the system frequency $(\mathrm{Hz})$

The maximum grid current $\mathrm{I}_{\mathrm{G}}$ is lastly calculated by (17):

$\mathrm{I}_{\mathrm{G}}=\mathrm{I}_{\mathrm{g}} \mathrm{D}_{\mathrm{f}}$ 
Step 5: Touch and Step Potential Criteria

One of the goals of a safe earthing grid is to protect people against lethal electric shocks in the event of an earth fault. The magnitude of ac electric current (at $50 \mathrm{~Hz}$ or $60 \mathrm{~Hz}$ ) that a human body can withstand is typically in the range of 60 to $100 \mathrm{~mA}$, when ventricular fibrillation and heart stoppage can occur. The duration of an electric shock also contributes to the risk of mortality, so the speed at which faults are cleared is also vital. Given this, we need to prescribe maximum tolerable limits for touch and step voltages that do not lead to lethal shocks.

The maximum tolerable voltages for step and touch scenarios can be calculated empirically from IEEE Std Section 8.3 for body weights of $50 \mathrm{~kg}$ and $70 \mathrm{~kg}$ :

Touch voltage limit - the maximum potential difference between the surface potential and the potential of an earthed conducting structure during a fault (due to ground potential rise):

- $50 \mathrm{~kg}$ person: $\mathrm{E}_{\text {touch } 50}=$

$$
\begin{aligned}
& \left(1000+1.5 \mathrm{C}_{\mathrm{s}} \rho_{\mathrm{s}}\right) \times \\
& \frac{0.116}{\sqrt{\mathrm{t}_{\mathrm{s}}}}
\end{aligned}
$$

- $70 \mathrm{~kg}$ person: $\mathrm{E}_{\text {touch } 50}=$

$$
\begin{aligned}
& \left(1000+1.5 \mathrm{C}_{\mathrm{s}} \rho_{\mathrm{s}}\right) \times \\
& \frac{0.157}{\sqrt{\mathrm{t}_{\mathrm{s}}}}
\end{aligned}
$$

Step voltage limit - is the maximum difference in surface potential experienced by a person bridging a distance of $1 \mathrm{~m}$ with the feet without contact to any earthed object it is given by (20) - (21) respectively.

- $\quad 50 \mathrm{~kg}$ person: $\mathrm{E}_{\text {step } 50}=$

$$
\left(1000+6 C_{s} \rho_{s}\right) \times \frac{0.116}{\sqrt{t_{s}}}
$$

- $\quad 70 k g$ person: $\mathrm{E}_{\text {step } 50}=$

$$
\left(1000+6 C_{s} \rho_{s}\right) \times \frac{0.157}{\sqrt{t_{s}}}
$$

Where $\mathrm{E}_{\text {touch }}$ is the touch voltage limit (V) $\mathrm{E}_{\text {step }}$ is the step voltage limit (V)
$\mathrm{C}_{\mathrm{s}}$ is the surface layer derating factor (as calculated in Step 2)

$\rho_{\mathrm{s}}$ is the soil resistivity $(\Omega . \mathrm{m})$

$\mathrm{t}_{\mathrm{s}}$ is the maximum fault clearing time ( $\mathrm{s}$ )

The choice of body weight $(50 \mathrm{~kg}$ or $70 \mathrm{~kg}$ ) depends on the expected weight of the personnel at the site. Typically, where women are expected to be on site, the conservative option is to choose $50 \mathrm{~kg}$.

\section{Step 6: Ground Potential Rise (GPR)}

Normally, the potential difference between the local earth around the site and remote earth is considered to be zero (i.e. they are at the same potential). However, an earth fault (where the fault current flows back through remote earth), the flow of current through the earth causes local potential gradients in and around the site. The maximum potential difference between the site and remote earth is known as the ground potential rise (GPR). It is important to note that this is a maximum potential difference and that earth potentials around the site will vary relative to the point of fault.

The maximum GPR is calculated by (22):

$$
\mathrm{GPR}=\mathrm{I}_{\mathrm{G}} \mathrm{R}_{\mathrm{g}}
$$

Where GPR is the maximum ground potential rise (V)

$I_{G}$ is the maximum grid current found earlier in Step 4 (A)

$R_{g}$ is the earthing grid resistance found earlier in $\underline{\text { Step } 3}(\Omega)$

\section{Step 7: Earthing Grid Design Verification}

Now we just need to verify that the earthing grid design is safe for touch and step potential. If the maximum GPR calculated above does not exceed either of the touch and step voltage limits (from $\underline{\text { Step }}$ 5), then the grid design is safe.

However if it does exceed the touch and step voltage limits, then some further analysis is required to verify the design, namely the calculation of the maximum mesh and step voltages as per IEEE Std 80 Section 16.5. 


\section{Mesh Voltage Calculation.}

The mesh voltage is the maximum touch voltage within a mesh of an earthing grid and is derived from IEEE Std 80 Equation 80 as given by (23):

$\mathrm{E}_{\mathrm{m}}=\frac{\rho_{\mathrm{s}} \mathrm{K}_{\mathrm{m}} \mathrm{K}_{\mathrm{i}} \mathrm{I}_{\mathrm{G}}}{\mathrm{L}_{\mathrm{M}}}$

Where : $\rho_{\mathrm{s}}$ is the soil resistivity $(\Omega . \mathrm{m})$

$\mathrm{I}_{\mathrm{G}}$ is the maximum grid current found earlier in Step 4 (A)

$\mathrm{K}_{\mathrm{m}}$ is the geometric spacing factor (see below)

$\mathrm{K}_{\mathrm{i}}$ is the irregularity factor (see below)

$\mathrm{L}_{\mathrm{M}}$ is the effective buried length of the grid (see below)

The geometric spacing factor $\mathrm{K}_{\mathrm{m}}$ is calculated from IEEE Std 80 Equation 81 given in (24):

$\mathrm{K}_{\mathrm{m}}$

$=\frac{1}{2 \pi}\left(\ln \left[\frac{\mathrm{D}^{2}}{16 \mathrm{~h} \times \mathrm{d}}+\frac{(\mathrm{D}+2 \mathrm{~h})^{2}}{8 \mathrm{D} \times \mathrm{d}}-\frac{\mathrm{h}}{4 \mathrm{~d}}\right]\right.$

$\left.+\frac{\mathrm{K}_{\mathrm{ii}}}{\mathrm{K}_{\mathrm{h}}} \ln \left[\frac{8}{\pi(2 \mathrm{n}-1)}\right]\right)$

Where $\mathrm{D}$ is the spacing between parallel grid conductors $(\mathrm{m})$

$\mathrm{h}$ is the depth of buried grid conductors (m)

$\mathrm{d}$ is the cross-sectional diameter of a grid conductor $(\mathrm{m})$

$\mathrm{K}_{\mathrm{h}}$ is a weighting factor for depth of burial $\mathrm{K}_{\mathrm{h}}=\sqrt{1+\mathrm{h}}$

$\mathrm{K}_{\mathrm{ii}}$ is a weighting factor for earth electrodes /rods on the corner mesh

- $\mathrm{K}_{\mathrm{ii}}=1$ for grids with earth electrodes along the grid perimeter or corners

- $\mathrm{K}_{\mathrm{ii}}=\frac{1}{2 \mathrm{n}^{\mathrm{n} / 2}}$ for grids with no earth electrodes on the corners or on the perimeter

$\mathrm{n}$ is a geometric factor (see below)
The geometric factor $\mathrm{n}$ is calculated from IEEE Std 80 Equation 85 as given in (25):

$\mathrm{n}=\mathrm{n}_{\mathrm{a}} \times \mathrm{n}_{\mathrm{b}} \times \mathrm{n}_{\mathrm{c}} \times \mathrm{n}_{\mathrm{d}}$

$\mathrm{n}_{\mathrm{a}}=\frac{2 \mathrm{~L}_{\mathrm{c}}}{\mathrm{L}_{\mathrm{p}}}$

Where: $\mathrm{n}_{\mathrm{b}}=1$ for square grids otherwise, $\mathrm{n}_{\mathrm{b}}=$ $\sqrt{\frac{L_{p}}{4 \sqrt{A}}}$

$\mathrm{n}_{\mathrm{c}}=1$ for square and rectangular grids otherwise,

$n_{c}=\left[\frac{L_{x} L_{y}}{A}\right]^{\frac{0.7 A}{L_{x} L_{y}}}$

$\mathrm{n}_{\mathrm{d}}=1$ for square, rectangular and L-shaped grids otherwise, $\mathrm{n}_{\mathrm{d}}=\frac{\mathrm{D}_{\mathrm{m}}}{\sqrt{\mathrm{L}_{\mathrm{x}}^{2}+\mathrm{L}_{\mathrm{y}}^{2}}}$

Where $\mathrm{L}_{\mathrm{c}}$ is the total length of horizontal grid conductors $(\mathrm{m})$

$\mathrm{L}_{\mathrm{p}}$ is the length of grid conductors on the perimeter $(\mathrm{m})$

$A$ is the total area of the grid $\left(\mathrm{m}^{2}\right)$

$\mathrm{L}_{\mathrm{x}}$ and $\mathrm{L}_{\mathrm{y}}$ are the maximum length of the grids in the $\mathrm{x}$ and $\mathrm{y}$ directions $(\mathrm{m})$

$\mathrm{D}_{\mathrm{m}}$ is the maximum distance between any two points on the grid (m)

The irregularity factor $\mathrm{K}_{\mathrm{i}}$ is calculated from IEEE Std 80 Equation 89 and presented in (27):

$\mathrm{K}_{\mathrm{i}}=0.644+0.148 \mathrm{n}$

Where $\mathrm{n}$ is the geometric factor derived in (25)

The effective buried length $\mathrm{L}_{\mathrm{M}}$ is found as follows:

- For grids with few or no earthing electrodes (and none on corners or along the perimeter):

$\mathrm{L}_{\mathrm{M}}=\mathrm{L}_{\mathrm{c}}+\mathrm{L}_{\mathrm{R}}$

Where $L_{c}$ is the total length of horizontal grid conductors (m)

$L_{R}$ is the total length of earthing electrodes $/$ rods $(\mathrm{m})$

- For grids with earthing electrodes on the corners and along the perimeter: 
$\mathrm{L}_{\mathrm{M}}$

$=\mathrm{L}_{\mathrm{c}}$

$+\left[1.55+1.22\left(\frac{\mathrm{L}_{\mathrm{r}}}{\sqrt{\mathrm{L}_{\mathrm{x}}^{2}+\mathrm{L}_{\mathrm{y}}^{2}}}\right)\right] \mathrm{L}_{\mathrm{R}}$

Where $\mathrm{L}_{\mathrm{c}}$ is the total length of horizontal grid conductors $(\mathrm{m})$

$L_{R}$ is the total length of earthing electrodes / rods (m)

$\mathrm{L}_{\mathrm{r}}$ is the length of each earthing electrode / $\operatorname{rod}(\mathrm{m})$

$\mathrm{L}_{\mathrm{x}}$ and $\mathrm{L}_{\mathrm{y}}$ are the maximum length of the grids in the $\mathrm{x}$ and $\mathrm{y}$ directions (m)

\section{E. Step Voltage Calculation.}

The maximum allowable step voltage is calculated from IEEE Std 80 Equation 92 and given by (30):

$\mathrm{E}_{\mathrm{S}}=\frac{\rho_{\mathrm{s}} \mathrm{K}_{\mathrm{s}} \mathrm{K}_{\mathrm{i}} \mathrm{Ig}_{\mathrm{g}}}{\mathrm{L}_{\mathrm{s}}}$

Where $: \rho_{\mathrm{s}}$ is the soil resistivity $(\Omega . \mathrm{m})$

$\mathrm{I}_{\mathrm{g}}$ is the maximum grid current found earlier in $\underline{\text { Step } 4}$ (A)

$\mathrm{K}_{\mathrm{s}}$ is the geometric spacing factor (see below)

$\mathrm{K}_{\mathrm{i}}$ is the irregularity factor (as derived above in the mesh voltage calculation)

$\mathrm{L}_{\mathrm{S}}$ is the effective buried length of the grid (see below)

The geometric spacing factor $\mathrm{K}_{\mathrm{s}}$ based on IEEE Std 80 Equation 81 is applicable for burial depths between $0.25 \mathrm{~m}$ and $2.5 \mathrm{~m}$ :

$$
\begin{aligned}
\mathrm{K}_{\mathrm{s}}=\frac{1}{\pi}\left[\frac{1}{2 \mathrm{~h}}\right. & +\frac{1}{\mathrm{D}+\mathrm{h}} \\
& \left.+\frac{1}{\mathrm{D}}\left(1-0.5^{\mathrm{n}-2}\right)\right]
\end{aligned}
$$

Where $\mathrm{D}$ is the spacing between parallel grid conductors $(\mathrm{m})$

$\mathrm{h}$ is the depth of buried grid conductors (m)

$\mathrm{n}$ is a geometric factor (as derived above in the mesh voltage calculation)
The effective buried length $\mathrm{L}_{\mathrm{S}}$ for all cases can be calculated by IEEE Std 80 Equation 93:

$\mathrm{L}_{\mathrm{S}}=0.75 \mathrm{~L}_{\mathrm{c}}+0.85 \mathrm{~L}_{\mathrm{R}}$

Where $L_{c}$ is the total length of horizontal grid conductors $(\mathrm{m})$

$L_{R}$ is the total length of earthing electrodes / rods $(\mathrm{m})$

Now that the mesh and step voltages are calculated, compare them to the maximum tolerable touch and step voltages respectively. If: $\mathrm{E}_{\mathrm{m}}<\mathrm{E}_{\text {touch }}$, and $\mathrm{E}_{\mathrm{s}}<\mathrm{E}_{\text {step }}$ then the earthing grid design is safe. If not, however, then further work needs to be done. Some of the things that can be done to make the earthing grid design safe:

- Redesign the earthing grid to lower the grid resistance (e.g. more grid conductors, more earthing electrodes, increasing cross-sectional area of conductors, etc). Once this is done, recompute the earthing grid resistance (see $\underline{\text { Step } 3 \text { ) }}$ and re-do the touch and step potential calculations.

- Limit the total earth fault current or create alternative earth fault return paths

- Consider soil treatments to lower the resistivity of the soil

- Greater use of high resistivity surface layer materials

In this example, the touch and step potential calculations for an earthing grid design will be performed. The proposed site is at Port Harcourt main of $132 / 33 \mathrm{KV}$ substation with a network connection via a transmission line and a delta-wye connected transformer.

\section{Step 1: Soil Resistivity}

The soil resistivity around the site was measured with a Wenner four-pin probe and found to be approximately $300 \Omega . \mathrm{m}$. 
Step 2: Surface Layer Materials

A thin $100 \mathrm{~mm}$ layer of blue metal $(3,000 \Omega . \mathrm{m})$ is proposed to be installed on the site. The surface layer derating factor is:

$\mathrm{C}_{\mathrm{s}}=1-\frac{0.09\left(1-\frac{\rho}{\rho_{\mathrm{s}}}\right)}{2 \mathrm{~h}_{\mathrm{s}}+0.09}$

By direct substitution of the above values of $\rho$ and $\rho_{\mathrm{s}}$ into (33) gives 0.7207.

Step 3: Earthing Grid Resistance

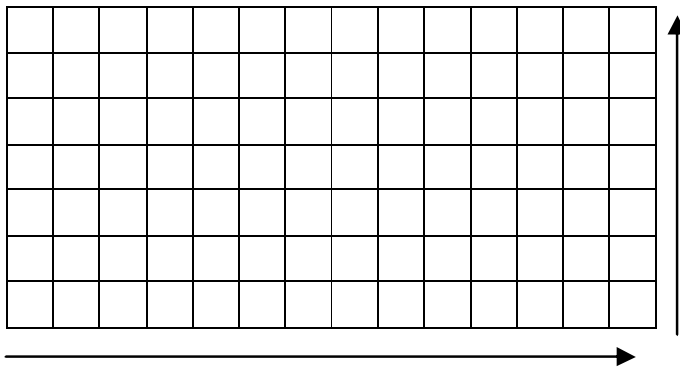

$90 \mathrm{~m}$

Figure 1. Proposed rectangular earthing grid

A rectangular earthing grid (see the figure right) with the following parameters is proposed:

- $\quad$ Length of $90 \mathrm{~m}$ and a width of $50 \mathrm{~m}$

- Grid conductors will be $120 \mathrm{~mm}^{2}$ and buried at a depth of $600 \mathrm{~mm}$

- 22 earthing rods will be installed on the corners and perimeter of the grid

- $\quad$ Each earthing rod will be $3 \mathrm{~m}$ long

Using the simplified equation, the resistance of the earthing grid with respect to remote earth is:

$$
\begin{gathered}
\mathrm{R}_{\mathrm{g}}=\rho\left[\frac{1}{\mathrm{~L}_{\mathrm{T}}}+\frac{1}{\sqrt{20 \mathrm{~A}}}\left(1+\frac{1}{1+\mathrm{h} \sqrt{\frac{20}{\mathrm{~A}}}}\right)\right] \\
=300\left[\frac{1}{956}+\frac{1}{\sqrt{20 \times 4500}}\left(1+\frac{1}{1+0.6 \sqrt{\frac{20}{4500}}}\right)\right]
\end{gathered}
$$

$=2.2753 \Omega$

\section{Step 4: Maximum Grid Current}

Suppose that the maximum single phase to earth fault at the $\mathrm{HV}$ winding of the transformer is $3.1 \mathrm{kA}$ and that the current division factor is 1 (all the fault current flows back to remote earth).

The $\mathrm{X} / \mathrm{R}$ ratio at the fault is approximately 15 , the maximum fault duration $150 \mathrm{~ms}$ and the system nominal frequency is $50 \mathrm{~Hz}$. The DC time offset is therefore given by (34):

$\mathrm{T}_{\mathrm{A}}=\frac{\mathrm{X}}{\mathrm{R}} \cdot \frac{1}{2 \pi \mathrm{f}}$

$\mathrm{T}_{\mathrm{A}}=0.04774 \mathrm{~s}$

The decrement factor is then given by (35):

$$
D_{f}=\sqrt{1+\frac{T_{a}}{t_{f}}\left(1-e^{-\frac{2 t_{f}}{T_{a}}}\right)}
$$

$50 \mathrm{~m}$

Substituting the respective values of $\mathrm{T}_{\mathrm{a}}$ and $\mathrm{t}_{\mathrm{f}}$ into (35) gives 1.1479.

Finally, the maximum grid current is got by substituting the values of $I_{g}$ and $D_{f}$ into (17)

$\mathrm{I}_{\mathrm{G}}=3.559 \mathrm{KA}$

\section{Step 5: Touch and Step Potential Criteria}

Based on the average weight of the workers on the site, a body weight of $70 \mathrm{~kg}$ is assumed for the maximum touch and step potential. A maximum fault clearing time of $150 \mathrm{~ms}$ is also assumed.

The maximum allowable touch potential is:

$$
\begin{aligned}
E_{\text {touch } 70}=( & \left.1000+1.5 \mathrm{C}_{\mathrm{s}} \rho_{\mathrm{s}}\right) \times \frac{0.157}{\sqrt{\mathrm{t}_{\mathrm{s}}}} \\
& =(1000+1.5 \times 0.7207 \\
& \times 3000) \times \frac{0.157}{\sqrt{0.15}} \\
& =1,720.04 \mathrm{~V}
\end{aligned}
$$

The maximum allowable step potential is

$\mathrm{E}_{\text {step 70 }}=\left(1000+6 \mathrm{C}_{\mathrm{s}} \rho_{\mathrm{s}}\right) \times \frac{0.157}{\sqrt{\mathrm{t}_{\mathrm{s}}}}=$

$(1000+6 \times 0.7207 \times 3000) \times \frac{0.157}{\sqrt{0.15}}=$

\section{$5,664.03 \mathrm{~V}$}

\section{Step 6: Ground Potential Rise (GPR)}

The maximum ground potential rise is:

$\mathrm{GPR}=\mathrm{I}_{\mathrm{G}} \mathrm{R}_{\mathrm{g}}=3559 \times 2.2753=8,097 \mathrm{~V}$ 
The GPR far exceeds the maximum allowable touch and step potentials, and further analysis of mesh and step voltages need to be performed.

\section{Step 7: Earthing Grid Design Verification}

\section{Mesh Voltage Calculation}

The components of the geometric factor $\mathrm{n}_{\mathrm{a}}, \mathrm{n}_{\mathrm{b}}, \mathrm{n}_{\mathrm{c}}$ and $\mathrm{n}_{\mathrm{d}}$ for the rectangular grid are:

$$
\begin{aligned}
& \mathrm{n}_{\mathrm{a}}=\frac{2 \mathrm{~L}_{\mathrm{c}}}{\mathrm{L}_{\mathrm{p}}}=\frac{2 \times 890}{280}=6.357 \\
& \mathrm{n}_{\mathrm{b}}=\sqrt{\frac{\mathrm{L}_{\mathrm{p}}}{4 \sqrt{\mathrm{A}}}}=\sqrt{\frac{280}{4 \sqrt{4500}}}=1.022 .
\end{aligned}
$$

Therefore the geometric factor is: $\mathrm{n}=\mathrm{n}_{\mathrm{a}} \times \mathrm{n}_{\mathrm{b}} \times$ $\mathrm{n}_{\mathrm{c}} \times \mathrm{n}_{\mathrm{d}}=6.357 \times 1.022 \times 1 \times 1=6.4939$. The average spacing between parallel grid conductors is:

$$
\begin{aligned}
\mathrm{D}=\frac{1}{2}\left(\frac{\mathrm{W}_{\mathrm{g}}}{\mathrm{n}_{\mathrm{r}}-1}\right. & \left.+\frac{\mathrm{L}_{\mathrm{g}}}{\mathrm{n}_{\mathrm{c}}-1}\right) \\
& =\frac{1}{2}\left(\frac{50}{6-1}+\frac{90}{7-1}\right) \\
& =12.5
\end{aligned}
$$

where $\mathrm{W}_{\mathrm{g}}$ and $\mathrm{L}_{\mathrm{g}}$ are the width and length of the grid respectively (e.g. $50 \mathrm{~m}$ and $90 \mathrm{~m}) n_{r} \mathrm{n}_{\mathrm{r}}$ and $\mathrm{n}_{\mathrm{c}}$ is the number of parallel rows and columns respectively (e.g. 6 and 7)

The geometric spacing factor $\mathrm{K}_{\mathrm{m}}$ is: $\mathrm{K}_{\mathrm{m}}$

$=\frac{1}{2 \pi}\left(\ln \left[\frac{\mathrm{D}^{2}}{16 \mathrm{~h} \times \mathrm{d}}+\frac{(\mathrm{D}+2 \mathrm{~h})^{2}}{8 \mathrm{D} \times \mathrm{d}}-\frac{\mathrm{h}}{4 \mathrm{~d}}\right]\right.$

$\left.+\frac{\mathrm{K}_{\mathrm{ii}}}{\mathrm{K}_{\mathrm{h}}} \ln \left[\frac{8}{\pi(2 \mathrm{n}-1)}\right]\right)$

$=\frac{1}{2 \pi}\left(\ln \left[\frac{12.5^{2}}{16 h \times d}+\frac{(12.5+2 \times 0.6)^{2}}{8 \times 12.5 \times 0.01236}\right.\right.$

$\left.-\frac{\mathrm{h}}{4 \times 0.01236}\right]$

$\left.+\frac{1}{1.26} \ln \left[\frac{8}{\pi(2 \times 6.4939-1)}\right]\right)=0.964$
The irregularity factor $\mathrm{K}_{\mathrm{i}}$ is: $\mathrm{K}_{\mathrm{i}}=0.644+$

$0.148 n=K_{i}=0.644+0.148 \times$

$6.4939=1.605$

The effective buried length $\mathrm{L}_{\mathrm{M}}$ is: $\mathrm{L}_{\mathrm{M}}=\mathrm{L}_{\mathrm{C}}+$

$\left[1.55+1.22\left(\frac{\mathrm{L}_{\mathrm{r}}}{\sqrt{\mathrm{L}_{\mathrm{x}}^{2}+\mathrm{L}_{\mathrm{y}}^{2}}}\right)\right] \mathrm{L}_{\mathrm{R}}=890+$

$\left[1.55+1.22\left(\frac{66}{\sqrt{90^{2}+50^{2}}}\right)\right] \times 66=$

$994.65 \mathrm{~m}$

Finally, the maximum mesh voltage is:

$E_{M}=\frac{\rho_{s} K_{M} K_{i} I_{g}}{L_{M}}=\frac{300 \times 0.964 \times 1.605 \times 3559}{994.65}=$

$1661 \mathrm{~V}$

The maximum allowable touch potential is $1,720 \mathrm{~V}$, which exceeds the mesh voltage calculated above and the earthing system passes the touch potential criteria (although it is quite marginal).

F. Step Voltage Calculation.

The geometric spacing factor $\mathrm{K}_{\mathrm{S}}$ is:

$\mathrm{K}_{\mathrm{s}}=\frac{1}{\pi}\left[\frac{1}{2 \mathrm{~h}}+\frac{1}{\mathrm{D}+\mathrm{h}}+\frac{1}{\mathrm{D}}\left(1-0.5^{\mathrm{n}-2}\right)\right]=$

$\frac{1}{\pi}\left[\frac{1}{2 \times 0.6}+\frac{1}{12.5+0.6}+\frac{1}{0.5}(1-\right.$

$\left.\left.0.5^{6.4939-2}\right)\right]=0.314$

The effective buried length $\mathrm{L}_{\mathrm{s}}$ is: $\mathrm{L}_{\mathrm{s}}=0.75 \mathrm{~L}_{\mathrm{c}}+$ $0.85 \mathrm{~L}_{\mathrm{R}}=0.75 \times 890+0.85 \times 66=$ $723.6 \mathrm{~m}$

Finally, the maximum allowable step voltage is:

$E_{S}=\frac{\rho_{s} K_{s} K_{i} I_{g}}{L_{s}}=\frac{300 \times 0.314 \times 1.605 \times 3559}{723.6}=$

$728 \mathrm{~V}$.

The maximum allowable step potential is $5,664 \mathrm{~V}$, which exceeds the step voltage calculated above and the earthing system passes the step potential criteria. Having passed both touch and step potential criteria, we can conclude that the earthing system is safe. 


\section{6) Computer Based Tools}

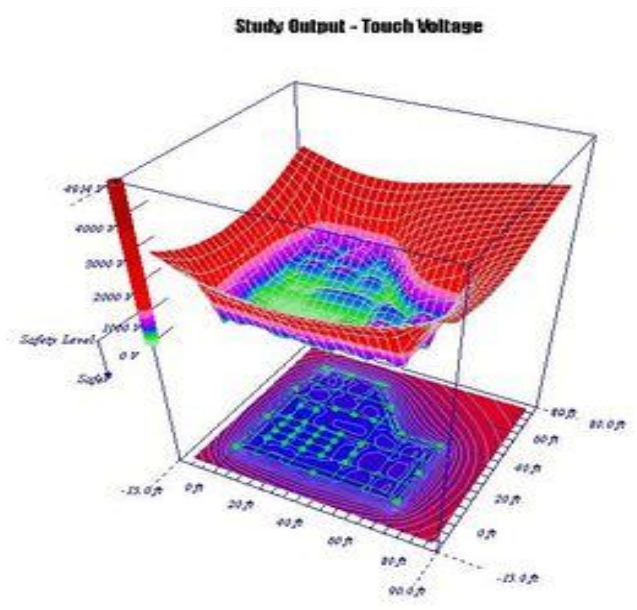

Figure 2. ETAP GroundMat software output

As can be seen from above, touch and step potential calculations can be quite a tedious and laborious task, and one that could conceivably be done much quicker by a computer. Even IEEE Std 80 recommends the use of computer software to calculate grid resistances, and mesh and step voltages, and also to create potential gradient visualisations of the site.

Computer software packages can be used to assist in earthing grid design by modeling and simulation of different earthing grid configurations. The tools either come as standalone packages or plug-in modules to power system analysis software (such as ETAP's Ground Grid Design Assessment).

The minimum size for the earthing grid conductors can be used to specify the earthing grid conductor sizes in the material take-offs and earthing drawings. The touch and step potential calculations (where necessary) verify that the earthing grid design is safe for the worst earth faults to remote earth. The earthing drawings can therefore be approved for the next stage of reviews.

\section{G. Etap Simulation of Earth Mat Results.}

The proposed data for the simulation are inputted in the Etap environment and results displayed.
Table 1. Earth Mat Simulation Result

\begin{tabular}{|l|l|l|l|l|}
\cline { 2 - 5 } \multicolumn{1}{c|}{} & $\begin{array}{l}\text { Calculat } \\
\text { ed } \\
\text { (Volts) }\end{array}$ & $\begin{array}{l}\text { Tolera } \\
\text { ble } \\
\text { (Volts) }\end{array}$ & $\begin{array}{l}\text { Optimal Number Of } \\
\text { Conductors }\end{array}$ \\
\hline $\begin{array}{l}\text { Tou } \\
\text { ch }\end{array}$ & 1588.8 & 1641.5 & $\begin{array}{l}\text { X- } \\
\text { DIRECTI } \\
\text { ON }\end{array}$ & $\begin{array}{l}\text { Y- } \\
\text { DIRECTI } \\
\text { ON }\end{array}$ \\
\hline Step & 1771.9 & 5667.4 & 7 & 14 \\
\hline
\end{tabular}

OPTIMAL NUMBER OF RODS $=9$

GPR $=14919.7$ VOLTS.

$\mathrm{R}_{\mathrm{g}}=1.35 \mathrm{ohms}$

\section{7) Conclusion.}

Substation earthing is a crucial part of substation design. The design has to be both safe and reliable. There are many steps to design a safe and effective grid. Manual calculations may be very tedious and difficult thus leading to incorrect results. Performing calculations and modifications to the design can be a long process. Computer programs have been developed to make the substation earthing design easier, and more accurate.

This project provides an overview of substation earthing and the most essential elements of a substation earthing grid design based on the IEEE Std. 80-2000. This project provides equations that are involved with a grid design. Finally an equation is provided using real world data. This example was designed to meet the design criteria for a safe ground grid

In this project, we have focused on earth mat design for large Substation. In the design optimization process, especially for complex systems, software simulation is essential. The step by step procedure for designing earth mat has been presented for which design parameters were obtained by ETAP Software. For earthing conductor and vertical earth electrode, Stainlessclad Steel rod type are used. LT side fault current is considered for earth mat design. 
Resistance value for all substations has been tested at site and achieved as less than 1ohm.It was found that the computer simulation method using Etap gives a satisfactory result in a quicker time than the manually operated method as shown in TABLE 1. Since the maximum GPR exceeded the touch and step potential, the earthing grid design is safe which conforms to the general acceptable IEEE design .

\section{REFERENCES}

[1] (2000) ANSI/IEEE Std.80, IEEE Guide for safety in AC Substation Earthing, New York,

[2] J.G. Sverak et al., Safe substation earthing, Part I: IEEE T. on Power Apparatus and Systems,100, 4281-4290, (1981); Part II: IEEE T. on Power Apparatus and Systems, 101, 4006-4023, (1982)

[3] F. Navarrina, I. Colominas, M. Casteleiro, Analytical Integration Techniques for Earthing Grid Computation by BEM, Num. Met. in Eng. and Appl. Sci., 1197-1206, CIMNE, Barcelona, (1992).

[4] I. Colominas, F. Navarrina, M. Casteleiro, A boundary element numerical approach for earthing grid computation, Comput. Methods Appl. Mech. Engrg., 174, 73-90, (1999).

[5] R.J. Heppe, Computation of potential at surface above an energized grid or other electrode, allowing for nonuniform current distribution, IEEE T. Power Apparatus and Systems, 98, 1978-1988, (1979).

[6] D.L. Garrett and J.G. Pruitt, Problems encountered with the Average Potential Method of analyzing substation earthing systems, IEEE T. on Power Apparatus and Systems, 104, 3586-3596, (1985).

[7] C. Mazett and G. M. Veca. "Impulse Behaviour of Earthing Electrodes”, IEEE Trans. Power App. Syst., Vol 102, no.6, PAS-9, 3148-3154, 1983.

[8] H.B. Dwight "Calculation of resistance to ground". Electrical Engineering, pp 1319- 1328, December 1936.

[9] S. Ghosh, S. Munshi, and J.R. Biswas. "Computer aided analysis of surge behaviour of an earthing counterpoise discharging impulse current to ground," Journal of the Institution of Engineers India, vol. 77, pp. 128-132, November, 1996.

[10] A.S. Farag, T.C. Cheng, and D. Penn."Earthing terminations of lightning protective systems", IEEE Trans. Dielectics Elect. Insul. Vo1.5 p p.869-877. 1998. 